\title{
PERCEPÇÕES SOBRE A LUDICIDADE: JOGOS E BRINCADEIRAS
}

\author{
Tânia Regina de Oliveira da Cruz ${ }^{1}$ \\ Vera Alves do Sacramento de Santana ${ }^{2}$
}

\begin{abstract}
Resumo
Esta pesquisa aborda percepções sobre a ludicidade: jogos e brincadeiras, destacando concepção sobre ludicidade; brinquedo, jogo e brincadeira; a importância da brincadeira; tipologia do jogo e a brincadeira como fator primordial na ludicidade. O brinquedo é a essência da infância e seu uso permite um trabalho pedagógico que possibilita a produção do conhecimento e também a estimulação da afetividade na criança. A criança estabelece com o brinquedo uma relação natural e consegue extravasar suas angústias e paixões; suas alegrias e tristezas, suas agressividades e passividades. Independente de época, cultura e classe social, os jogos e os brinquedos fazem parte da vida da criança, pois elas vivem num mundo de fantasia, de encantamento, de alegria, de sonhos, onde realidade e faz-de-conta se confundem. Para o desenvolvimento deste estudo foi adotado o método descritivo, com abordagem qualitativa e quantitativa sobre o tema em questão. O referido trabalho foi desenvolvido com base em observações e pesquisa bibliográfica com a finalidade de construir um embasamento teórico a partir de conhecimentos já catalogados como: livros, artigos científicos, revistas, relatórios, publicações periódicas, internet entre outras fontes. Concluiu-se que os jogos e brincadeiras, presentes na vida de qualquer indivíduo é uma atividade natural do ser humano.
\end{abstract}

Palavras-chave: Ludicidade. Jogos. Brincadeiras. Aprendizagem.

\begin{abstract}
This research approaches perceptions about playfulness: games and games, highlighting conception about playfulness; toy, game and play; the importance of play; typology of the game and play as a primary factor in playfulness. The toy is the essence of childhood and its use allows a pedagogical work that enables the production of knowledge and also the stimulation of affection in children. The child establishes a natural relationship with the toy and is able to vent his anxieties and passions; their joys and sorrows, their aggressiveness and passivities. Regardless of time, culture and social class, games and toys are part of the child's life, as they live in a world of fantasy, enchantment, joy, dreams, where reality and make-believe are mixed. For the development of this study the descriptive method was adopted, with qualitative and quantitative approach on the subject in question. This work was developed based on observations and bibliographic research in order to build a theoretical basis from knowledge already cataloged as: books, scientific articles, magazines, reports, periodicals, internet and other sources. It was concluded that the games and games present in the life of any individual is a natural activity of the human being.
\end{abstract}

Keywords: Ludicity. Games. Just kidding. Learning.

\footnotetext{
1 Doutoranda em Ciências da Educação pela Faculdade Interamericana de Ciências Sociais FICS.Mestra em Ciências da Educação pela Faculdade Interamericana de Ciências Sociais - FICS. Especialista em Docência do Ensino Superior pela faculdade Católica de Ciências Econômicas da Bahia - FACCEBA. Especialista em Politicas Públicas pela Universidade da Integração Internacional da Lusofonia Afro - Brasileira - UNILAB. Graduada em Educação Física (licenciatura) pela Universidade Católica de Salvador- UCSAL. Professora da Rede Municipal e da Faculdade Regional de Filosofia, Ciências e Letras de Candeias - FAC.Email: taniaregina2730@gmail.com

2 Mestre pela Faculdade Interamericana de Ciências Sociais- FICS. Graduada em Pedagogia pela Faculdade Regional de Filosofia, Ciências e Letras de Candeias. Especialista em Metodologia e Didática do Ensino Superior pela Faculdade São Bento da Bahia, Especialista em Alfabetização e Letramento nas Séries Iniciais, Educação de Jovens e Adultos, Especialista em Psicopedagogia Institucional ambas pela Instituição Superior de Educação de Afonso Cláudio. Docente nas Séries Iniciais do Ensino Fundamental na Prefeitura Municipal de Camaçari-Bahia.
} Email:joverasme@bol.com.br 


\section{Introdução}

Esta pesquisa objetiva uma reflexão acerca do jogo e do brinquedo no campo da educação refletindo como os mesmos contribuem para o processo ensino aprendizagem, estimulam a socialização e colaboram para a diminuição da animosidade entre os seus participantes. O jeito de lidar, organizar, propor, respeitar e valorizar as brincadeiras das crianças demonstra, através da história da infância, o entendimento que se tem das crianças. O que se observa ao longo dessa narrativa é que sempre existiu formas, jeitos e instrumentos para se brincar, como por exemplo; a bola, cantigas de roda, jogar pedrinhas, brinquedos e uma forma de brincar muito antiga. Para Vygotsky (2005, p. 92):

O brincar é definido pela situação imaginária criada pela criança, e que tende a suprir necessidades que mudam conforme a idade. Com o crescimento surgem novas necessidades que poderão ser satisfeitas através da capacidade imaginária da criança.

Vygotsky entende a brincadeira como uma atividade movida pela imaginação, atividade consciente, que se desenvolve conforme seu crescimento. Considerando as brincadeiras e os jogos como atividades privilegiadas para a formação do desenvolvimento e da aprendizagem na criança e partindo do entendimento de jogo enquanto enfatizado e possibilitado de interferências na formação da criança psicofísico e social, surge a seguinte investigação: A ludicidade através de jogos e brincadeiras contribuem no processo ensino aprendizagem?

Através do brincar a criança experimenta, organiza-se, regula, constrói normas para si e para o outro. Portanto, o bom professor e aquele que ajuda ao seu aluno a construir seu próprio conhecimento. A partir da sua vivência, trabalhando com metodologia inovadora, contribuindo de uma maneira especial com o desenvolvimento afetivo cognitivo da sua clientela.

Esta pesquisa tem como objetivos específicos investigar como o lúdico vem sendo caracterizado e credibilidade; identificar os fatores que favorecem e dificultam a prática do lúdico; analisar como o brinquedo e o jogo têm sido desenvolvidos; verificar se o lúdico tem sido usado como elemento essencial no desenvolvimento físico, afetivo, intelectual e social da criança.

Dessa forma, para auxiliar uma melhor compreensão acerca dos objetivos e questões de estudos aborda-se teorias de alguns autores que pudessem de fato 
contribuir com as reflexões, e houvesse uma integração entre os conhecimentos empírico e científico.

Faz-se necessário abordar o assunto "Jogos e brincadeiras infantis" não apenas como simples entretenimento, mas como atividades que possibilitem a aprendizagem de várias habilidades. Tendo como objetivo relacionar o lúdico, a brincadeiras da infância, com recursos capazes de contribuir para o desenvolvimento das funções cognitivas da criança, bem como fazer associações da atividade nervosa à cognição.

\section{Concepção Sobre Ludicidade}

O estudo de escritos básicos da didática manuscritos por filososfos mostra que, a partir da ancianidade, existia quem justificasse a concepção da atuação particular do aprendiz como impulsionadora de seu avanço intelectivo (a exemplo dos grandes filósofos Sócrates, Santo Antonio, Montaigne) e o prestimo da recreação no aprendizado ( evidenciado por Platão em A República). O que se repete, deste 0 século XVIII, é a consolidação dessas ideologias, que se confrontavam ao que então era cogitado ser a metodologia acadêmica fundamental (OLIVEIRA, 2011).

Refere-se a um conteudo dificil, agora, é preciso a formação de várias zonas de saberes, com intenção de planejar aprendizados de qualquer segmento desse procedimento que possa atrelar a teoria e a prática. Nessa perspectiva, manifestamse as cooperações teóricas que inspiraram o método, a instrução e o conhecimento por meio do lazer.

Ensinar garotos menores de 06 anos de diversas situações sociais já era um ponto debatido por Comênio (1592-1670) mestre e presbitero evangélico tchecoslovaco em sua obra "A escola da infância", publicado em 1628, onde declarava que o nível introdutório de educação era o "colo de mãe" e necessitaria acontecer no interior de casa. Já em 1637 criou um projeto de escola materna em que sugeria o uso de equipamentos audiovisuais, como livros iconográficos, para ensinar crianças pequenas. Somos capazes de igualmente compreender que:

O cultivo dos sentidos e da imaginação precedia o desenvolvimento do lado racional da criança. Impressões sensoriais advindas da experiência com manuseio de objetos seriam internalizadas e futuramente interpretadas pela razão. Também a exploração do mundo no brincar era vista como uma forma de educação pelos sentidos. Daí sua defesa de uma programação bem elaborada, com bons recursos materiais e boa racionalização do tempo e do espaço escolar, como garantia da boa "arte de ensinar", e da ideia de que 
fosse dada à criança a oportunidade de aprender coisas dentro de um campo abrangente de conhecimentos (OLIVEIRA, 2011, p. 37).

Através de equipamentos educativos como lousa, modelos e trabahos diversos, como passeios, necessitariam ser feitos com as crianças respeitando a sua faixa etária, ajudando-as a fortalecer ações teóricas, incentivar seu dialogo vocal.

O pensador Jean Jacques Rousseau (1712-1778) elaborou uma orientação pedagógica em que reprovava intolerâncias, tiranias e todas as entidades comunitárias que coagissem a soberania peculiar do mundo. Era contrario a ação domestica atual de transferir a competência dos filhoa aos professores, para que estes agissem com rigor, e salientava o oficio da genitora como proceptora original da criança (ROUSSEAU, 1995).

Inovou a educação no seu periodo ao declarar que a puericia não era tão somente uma via de acesso, uma etapa de formação para a vida madura, todavia tinha valia de natureza igual. Competiria ao mestre retirar tudo o que impedisse a criança de ter uma vivência plena de seu momento. Ao invés do afastamento desconhecido, recomendava que a educação optasse pela autononia e o ritmo da natureza, contradizendo os ensinamentos religiosos do período, onde os adultos evangelizavam exercendo poderes sobre as crianças (NISBET, 1992).

Rousseau argumentava por uma educação não instruída pelos adultos, porém que existisse uma resposta do desprendido funcionamento das competências infantis e destacasse não o que lhe é permitido conhecer, todavia o que ela é capaz de conhecer (OLIVEIRA, 2011).

Pestalozzi (1746-1827), da mesma forma comportou-se em oposição ao intelectualismo exagerado da educacional tradicional. Acreditava que a rigidez obrigatória da educação permanenceria na bondade e no amor, igual como acontece na familia, e firmava que a educação teria que atender a evolução amorosa das crianças a partir de sua origem.

Lecionar deveria ocorrer em um local o mais espontâneo possivel, em um ambiente de muita harmonia, com disciplina rigosa , porém amorosa, e por em prática o que já é trazido pela criança, o que contribuiria para a construção da indole infantil. Ainda enfatizou a relevância do desenvolvimento da destreza através da aplicação de trabalhos manuais para as crianças (TEIXEIRA, 1995).

A adaptação de métodos de ensino ao nível de evolução dos aprendentes pode acontecer através da interferência de trabalhos com músicas, arte, jogos de 
soletração, geografia e aritmética, além de muitas outras atividades utilizando linguagem oral e de contato direto com a natureza. Movimentou posteriormente a ideia de agilidade, uma vez que já estava presente em Rousseau, e de composição formada do estudo, do mais simples ao mais complexo, que já aparecia em Comênio. Sua pedagogia destacava ainda a carência de a escola treinar a vontade e crescer as ações morais dos alunos (INCONTRI,1997).

Froebel (1782-1852), criou em 1837 um kindergarten denominado de "jardim de infância", onde crianças e adolescentes, nos quais são minúsculos fatores que, adubadas e desenvolvidos a circunstâncias pertinentes em seu meio ambiente, abririam sua alma em uma atmosfera de amor, amizade e estímulo, permanecendo com a opção de aprender sobre si mesmos e sobre o mundo. Este era concebido como um todo em que cada pessoa seria ao mesmo tempo uma unidade e uma parte dele (TEIXEIRA,1995).

No pensamento de Froebel existia uma preocupação com a moldagem das crianças, que advinha de um entendimento de fora o que diferenciava os jardins de infância das casas existenciais no periodo, por abarcar uma dimensão pedagógica, qunto da escola, que apresentava ter. E então ele desenvolveu musicas e brincadeiras para nutrir emoções e sensações, destacou o porte educacional da ação prática, criou jogos para o conhecimento da aritmética e da geometria, propôs ainda que as tarefas educativas atrelassem conversas e poesias e o plantio da horta pelas crianças.

A manipulação de peças e a atuação em tarefas diversificadas de livre expressão por intermédio da música, mimicas, projetos, entre outros poderiam facilitar para que o universo interior da criança se mostrasse, com o proposito de velas evoluir, notar-se , imarginar-se e descobrir soluções.

Os trabalhos manifestavam a modificação de materiais que eram usados em atividades de modelagem, dobradura, decalques, como: papel, areia, barro entre outras atividades manuais que serviriam para incentivar a criança no seu desenvolvimento de atividades de formação individual e posteriormente coletiva. As músicas por sua vez agregariam esta relação de atividades e materiais. As prendas e os trabalhos se inteligariam através da intervenção da facilitadora na composição da livre demonstração da criança, isto é, daquelo que o escritor, dentro das suas conviçcões, intitulou de ações maternas (TEIXEIRA, 1995). 
Maria Montessori (1879-1952) engloba-se igualmente na relação dos grandes construtores de planejamentos estruturados para a Educação Infantil no século XX. Ficando com a incumbência de produzir metodos de ensino com sustentação na aplicação de materiais próprios para lidar com crianças com deficiência mental. Foi requisitada a aparelhar uma sala para educação de crianças que não tinham deficiências no meio de uma casa coletiva que fora designada a familias dos setores populares, experimento que chamou "Casa das Crianças" (MONTESSORI, 1970).

Do comportamento de brincar para o material estruturador da atividade própria da criança - o brinquedo - Montessori produziu materiais especiais voltados para a motricidade unidos acima de tudo, à atividade de cuidado individual dos sentidos e do intelecto, como por exemplo ábaco, que é utilizado para o aprendizado de operações matemáticas, letras móveis, letras recortadas entre outras atividades. Ela reconheceu a necessidade da adequação dos moveis usados pelas crianças para um tamanho que fosse mais apropriado para a faixa etária, bem como os utensilios que seriam usados para as brincadeiras na casinha de boneca.

Um dos educadores que promoveu a inovação das práticas de ensino no período foi Celestin Freinet. Ele afirmava que a educação que a instituição dava para as crianças teria que ir além da sala de aula extrapolando assim os limites preestabelecidos favorecendo com isso a integração e suas vivências num contexto social, beneficiando ao máximo a autoexpressão o que como certeza traria um envolvimento maior no que tange a participação em ações cooperativas, possibilitando uma demanda significativa no trabalho partilhado e em atividades de ordem coletiva, básicos para o desenvolvimento (FREINET, 1975).

No seu ponto de vista, as práticas manuias e intelectivas possibilitam a elaboração de uma obediência pessoal e a formação do exercício - jogo, que liga o ludico e é por ele considerado como alicerce fundamental de uma escola publica. A pedagogia de Freinet organiza-se ao redor de uma série de técnicas ou atividades, entre elas as aulas-passeio, o desenho livre, o texto livre, o jornal escolar, a correspondência interescolar, o livro da vida. Inclui ainda oficinas de trabalhos manuais e intelectuais, o ensino por contratos de trabalho, a organização de cooperativas na escola (NICOLAU,1998).

Perante o exposto, esses teoricos favoreceram com seus estudos relacionados à infância e a ludicidade, abrindo trajetórias com uma maior contemporização e 
novidade no paradgma de educação infantil nas escolas, abrindo assim um espaço no mercado por meios diversos: roupa, brinquedos, musica entre outros. Isto é, deu uma nova abordagem pedagogica, que levou os educadores a um questionamento das suas práticas e os impulsionaram a procurarem formação básica ou especializada, e:

Dessa forma, a criança brinca porque é "indispensável ao seu equilíbrio afetivo e intelectual que possa dispor de um setor de atividade cuja motivação não seja a adaptação ao real senão, pelo contrário, a assimilação do real ao eu, sem coações nem sanções (NICOLAU, I1998, p. 68).

A brincadeira é, então uma atividade que transforma o real, por assimilação quase pura às necessidades da criança, em razão dos seus interesses afetivos e cognitivos. O jogo, devido a abrangência de significados, é uma forma de expressão da linguagem afetiva e refere-se àquele cuja estrutura é o símbolo. Piaget (1998), caracteriza o brincar como uma atividade que reflete os estados internos do sujeito diante de uma realidade vivida ou imaginada (NICOLAU, 1998).

O brincar é a linguagem típica da criança por ser mais expressiva que a linguagem verbal. Esta razão levou-o a atribuir ao jogo um papel de complemento imprescindível à análise da criança. O jogo representa, ainda, o equivalente ao lúdico da fantasia, além do que, atualiza suas imaginações inconscientes, sexuais e agressivas, seus desejos e suas experiências vividas (PIAGET, 1998).

Os estudos de Piaget oferecem contribuições principalmente ao analisar o simbolismo secundário do jogo, compreendido como "o simbolismo menos consciente que o das ficções comuns" (Ibid, 1998, p. 93). O jogo de ficção corresponde à manifestação mais importante na criança, que é o pensamento simbólico consciente. Em relação à aprendizagem, a ludicidade oferece indícios relevantes a respeito dos aspectos emocionais envolvidos no processo de conhecer e de aprender e sendo assim pode-se destacar que:

Do ponto de vista teórico, possibilita-nos compreender os processos e estruturas psicológicas graças às quais o ser humano produz conhecimento; do ponto de vista prático, possibilita-nos analisar criticamente as situações que são mais favoráveis para isso. Jogos regras e de construção são essencialmente férteis o sentido de criarem um contexto de observação e diálogo, dentro dos limites da criança, sobre processos de pensar e construir conhecimentos. (MACEDO, PETTY e PASSOS, 2005, p. 121).

Muitos trabalhos com jogos de regras foram inspirados no construtivismo de Piaget, para compreender a estrutura cognitiva das crianças, bem como favorecer os processos construtivos do pensamento e a aprendizagem de forma geral.Dessa 
forma, por meio da ludicidade, a criança organiza e pratica regras, elabora estratégias e cria procedimentos a fim de vencer as situações-problemas referentes aos aspectos afetivo-sociais e morais, pelo fato de exigir relações de reciprocidade, cooperação e respeito mútuo (PIAGET, 1998).

É na brincadeira que a criança se comporta além do comportamento habitual de sua idade, seu comportamento diário; afirma que apesar do brinquedo não ser aspecto dominante da infância, ele exerce uma enorme influência no desenvolvimento infantil (VYGOTSKY, 2010).

Neste sentido, é importante que se saiba o quanto é relevante a utilização das brincadeiras infantis, pois a criança sente-se motivada e o educador inova sua prática, consegue êxito no processo ensino aprendizagem e posteriormente, leva a criança a penar e interagir de forma mais dinâmica com seu meio. Deve-se compreender o brincar como ação fundamental para o desenvolvimento da pessoa e dos grupos sociais, em diferentes épocas e espaços.

Pois, o brincar é natural, quando se brinca, fica-se altamente concentrado.Existe a necessidade de se usar a ludicidade com mais intensidade, pois a brincadeira é universal e é própria da saúde. O brincar facilita o crescimento, conduz aos relacionamentos grupais (Ibid, 2010). Contudo, ao planejar atividades lúdicas é importante que o educador tenha em mente que quando brinca a criança experimenta, descobre, inventa, aprende e confere habilidades, além de desenvolver competências, estimular a autoconfiança e a autonomia, proporcionar o desenvolvimento da linguagem, do pensamento, da concentração e atenção que são essenciais ao bom desempenho da criança na escola e na vida.

\section{Brinquedo, Jogo e Brincadeira}

É de extrema importância a universalidade atribuída ao lúdico e os seus caracteres. O brinquedo, o jogo e a brincadeira são elementos indispensáveis no processo de ensino e aprendizagem do educando. Ainda pode-seperceber que:

Para a criança o brinquedo pode ser visto como objeto, suporte de brincadeira, esta como a descrição de uma conduta, estruturada, com regras e o jogo para designar tanto o objeto e as regras do jogo da criança brinquedos e brincadeiras (KISHIMOTO, 1994, p. 48)

Para a criança, a brincadeira é a melhor maneira de se comunicar, um meio para perguntar e explicar, um instrumento que ela tem para se relacionar com outra 
criança. O brinquedo as ajuda a elaborar papéis que terão de exercer no futuro. É uma invasão ao mundo dos adultos, mas com aspecto desinteressado que só a imaginação pode oferecer. $O$ brinquedo é instrumento que lhes possibilita a expressão criativa de seus sentimentos em relação ao mundo que as rodeia e que ainda não compreendem.

Conforme Huizinga, estudioso sobre a relação existente entre o jogo, cultura, e sua função social desde as sociedades mais primitivas até as civilizações mais complexas, pois:

A cultura surge sob a forma de jogo, sendo que a tendência lúdica do homem está na base de muitas realizações na esfera da Filosofia, da Ciência, da Arte, especialmente da música e da poesia. Para eles, além dos jogos que são normalmente incorporados à cultura de um povo, a própria cultura se forma $\mathrm{e}$ se desenvolve impulsionada pelo espírito lúdico (HUIZINGA, 1971, p. 53).

Compreende-se o jogo segundo a cultura no sentido de brincadeira e da criatividade, que vem ganhando mais espaço de compreensão como educação, uma vez que os próprios educadores têm tomado consciência de toda sua capacidade de criar e valorizar de seus alunos começando a ver que brincar é coisa séria, pois percebe-se que:

O brinquedo é o suporte da brincadeira, quer seja concreto ou ideológico, concebido ou simplesmente utilizado como tal ou mesmo puramente fortuito. $O$ brinquedo é o objeto de conhecimento nas mãos do educando, com ele a criança imagina, cria e fantasia (BROUGÉRE, 2004, p.28)

É imprescindível salientar que o brinquedo se torna mais significativo a partir da sua construção, ou seja, quando a criança utiliza materiais para construir seu próprio objeto de brincar, o valor deste é mais rico devido à participação dela na construção do mesmo. Porém, vale salientar que esse brinquedo só consegue atingir um sentido lúdico quando de fato foi considerado alicerce de brincadeira, em especial, quando as crianças são despertadas para atrelar a mesma com a sua rotina social. Tratando dos fatos memoráveis relacionados ao brinquedo o que a faz insere-se à história de vida, fato esse que a permite transitar naquele momento em diferentes culturas e espaços sociais.

Assim, à medida que a criança evolui, por consequência o brinquedo também avança, seja no seu formato, seja no seu significado. A infância é um momento de apoderar-se de imagem e de representações diversas que percorrem diferentes vias. As suas fontes são diversificadas. Ao brincar a criança percebe o objeto como ele é, mas dá-lhe um novo significado este é mais relevante do que o objeto propriamente 
dito, pois a criança elabora novas relações entre situações imaginárias e reais. Essa capacidade de brincar torna possível a decifração de mistérios que nos rodeiam.

A brincadeira é o instante sobre si mesmo e sobre o mundo, dentro de uma realidade de fantasia. É através dela que a criança simboliza o discurso externo e o interioriza, criando pensamento próprio. Além do mais, a brincadeira abre espaços para o jogo da linguagem com o imaginário, apresentando-se como possibilidade da criança inventar novas formas de compreensão do contexto sociocultural em que vive, e construir valores e saberes. Assim, o brincar consiste numa fonte de crescimento e aprendizagem. É possível conhecer mais claramente as funções mentais, como o desenvolvimento do raciocínio e da linguagem através da relação da brincadeira e o avanço da criança, pois:

O jogo infantil torna-se mais próximo da arte, considerando a necessidade da criança criar para si o mundo ao contrário. Para entendê-lo melhor. Os jogos e brincadeiras propiciam à criança alicerce para subjetividade e compreensão do mundo (VYGOTSKY, 1998, p. 94)

Além disso, através desses, a criança se comunica com o meio e se expressa, constrói e socializa o saber na interação de experiências com outras crianças, tornando possível que trabalhos e habilidades sejam cumpridas de maneira autônoma, ou mesmos com a colaboração dos colegas, evidenciando as zonas de desenvolvimento proximal dessas atividades lúdicas.

\section{A importância da Brincadeira}

Compreender a origem e o significado dos jogos tradicionais infantis requer a investigação das raízes folclóricas responsáveis pelo seu surgimento. Diversos estudos clássicos destacam a determinação das origens brasileiras na mistura de três raças ou na assimilação progressiva, nos primeiros séculos, das raças vermelha e negra pela raça branca, na figura dos primeiros portugueses colonizadores. Percebese que:

Em 1532 organizou-se a sociedade brasileira, os portugueses já tinham, pelo menos, um século de experiência de convívio com os trópicos, na índia e África, facilitando sua adaptação na nova terra. A colonização portuguesa se instalava em São Vicente e Pernambuco, ancorada pela família patriarcal, apoiada no trabalho escravo, na união dos portugueses com a mulher índia, formando-se aqui uma sociedade agrária, de estrutura escravocrata, de exploração econômica, híbrida do índio e, mais tarde, do negro (FREIRE, 1963, p. 69). 
Existiam com primeiros jogos e brincadeiras infantis atividades voltadas à natureza, tais como passeios no mato, brincadeiras de petecas, bolas e banhos de rio entre outras. Quando o país passou a ser colonizado por Portugal surgiram assim outras possibilidades de brincadeiras como pipas, dominó entre outros, e:

\begin{abstract}
A mistura do índio e negro ao branco fez prevalecer como núcleo primitivo para a formação da nacionalidade brasileira o elemento branco. Assim, quando chegaram as levas de imigrantes estrangeiros, já existia um núcleo primitivo de população no qual predominava o elemento branco. Com a mistura das populações veio também seu folclore. Ao longo do processo de miscigenação, o folclore brasileiro recebeu nova cor, tomou novos aspectos (KISHIMOTO 1993, p. 19).
\end{abstract}

Afirmava-se ainda que:

É impossível definir com precisão o que há de especificamente português na
cultura brasileira. Como isolar o radical luso, do complexo de valores de
ordem material e espiritual que constituem patrimônio comum do Ocidente?
Que determinado comportamento social corresponde aquilo a que chamamos
cultura luso-brasileira? É uma questão complicada, pois o português recebeu,
por seu lado, grande influência europeia, africana e peninsular, antes de
aportar ao Brasil (BITTENCOURT, 1993, p. 40).

Com os primeiros colonizadores surgiu o folclore lusitano, cheios de ação como história, cantos, superstições e lendas que se eternizaram pelas vozes doces das afrodescendentes, e também as festas, técnicas, valores e jogos. No Brasil os papagaios de papel que são de origem oriental passaram a ser visto como brinquedos infantis. A origem provavelmente oriental da pipa é também ressaltada por Cascudo (1988). Os portugueses trouxeram o papagaio do Oriente, Japão e China, onde é popular, em todas as classes sociais, desde remotíssimo tempo.

\title{
Tipologia do Jogo
}

A recreação é uma ação que beneficia o físico e a mente tanto no que tange ao desenvolvimento individual como social, de forma total e graciosa. $O$ jogo passa a ser um aliado da criança, pois faz com que haja uma evolução tanto da criança com o jogo como do jogo com a criança ajudando com isso no seu desenvolvimento. Ou seja, funcionando como integrador da sua evolução, uma vez que:

O jogo é uma atividade muito importante, pois através dele a criança cria uma zona de desenvolvimento proximal, funções que ainda não amadureceram, mas que se encontram em processo de maturação, o que a criança irá alcançar em um futuro próximo (VYGOTSKY, 1998, p. 108). 
Com este olhar, a escola deve ser cheia de vivências para a investigação eficiente, associada por crianças e adultos no qual através dos jogos e brincadeiras a criança realiza diversas atuações com as quais compartilha no dia a dia. A práxis do jogo mostra uma coerência da parcialidade tão fundamental para a formação do caráter humano quanto ao método definitivo dos suportes intelectivos. Ele é bemintencionado, pois presume uma conduta do homem sobre a existência, e é uma atuação cheia de reducionismo, que só faz reforçar o incentivo e a possibilidade de novas intervenções.

Piaget (1973), defende a ideia de desenvolvimento humano a partir das ações que o sujeito exerce sobre o ambiente. E nos estudos sobre jogos sistematizou os seguintes jogos: jogos de exercício, no período pré-operatório, de dois a sete anos de idade; e jogos de regras, a partir de sete anos de idade. Na fase sensório motor, a criança desenvolve seus sentidos, seus movimentos, seus músculos, sua percepção e seu cérebro. O bebê brinca com o corpo, executa movimentos como estender e recolher os braços, as pernas, os dedos, os músculos.

As diversões físicas atendem à criança, pois os movimentos simples estabelecem uma conexão com as necessidades de seu crescimento isso de forma bem natural, suprimindo as parcerias diferentes dos músculos, ocorrendo a melhoria. Neste instante, os jogos funcionam como exercício, onde sua fonte se posiciona no desempenho autêntico dos aparelhos propulsores da criança. Nessa fase, a criança necessita do adulto por inteiro, tornando imprescindível a sua presença nas relações sociais, que por sua vez auxiliam no desenvolvimento do adulto com a criança é caracterizada como o primeiro sinal da educação lúdica.

Os dois primeiros anos de vida, os atos das crianças são direcionados a satisfação de suas próprias necessidades, e em algum momento, para aquisição de prazer. Os atos voluntários feitos por elas como engatinhar, andar e falar, etc., remetem bastante prazer para as crianças. Observando tais condutas constatou que a repetição incessante das mesmas tem o objetivo de realizar o prazer de exercitar estruturas já aprendidas, o que dá a criança a sensação de eficácia e poder (PIAGET, 1975).

O jogo de ação é, então, especifico deste estágio sensório-motora. Todavia, a práxis dos jogos de ação não será excluída nos estágios seguintes. A cada nova abordagem eles serão revistos e aplicado, até mesmo quando chegar na vida adulta. 
A vista disso pode-se afirmar quer o jogo de ação não objetiva o conhecimento em si, porém a sua formação de técnicas de ação, de condução, de automatismo, é indispensável a performance do ser humano.

A fase simbólica, marcada pelo jogo simbólico e faz-de-conta. Esta é caracterizada pela imitação onde à criança reelabora criativamente tudo aquilo que ouve, especialmente histórias e contos. Já a brincadeira torna-se uma diversão de risco e gratuidade na qual o prazer opõe-se a curiosidade (lbid, 1975).

Esta fase ainda se caracteriza pela etapa egocêntrica, onde o educando se torna centro das atenções e dos acontecimentos, sendo assim, o jogo com regras não funciona. Por esta razão é necessário que a criança nessa fase seja convidada a viver em grupos, socialmente para que haja um maior crescimento pessoal e intelectual. No processo de desenvolvimento da criança, os jogos simbólicos, como estrutura, veem depois dos jogos de exercício e pode-se afirmar que:

\begin{abstract}
Esse tipo de jogos caracteriza-se pela assimilação deformante porque nessa situação a realidade é assimilada por analogia, como a criança pode ou deseja. Isto é, os significados que ela atribui aos conteúdos de suas ações, quando joga, são deformações dos significados correspondentes na vida social ou física (VYGOTSKY, 2005, p. 98).
\end{abstract}

As crianças podem por puro instinto inventar brincadeiras. Essas criações executadas nos modos dos jogos figurados e os métodos obtidos nos jogos de ação serão futuramente fatores das intervenções mentais. O que irá favorecer a inserção da criança a um universo social progressivamente mais complicado.

Seguindo a óptica estrutural, os jogos figurados possuem, do mesmo modo, uma relevância capital no que tange a elaboração do saber na escola. O significado e a utilidade de opinião desenvolvem-se e obtêm cenário nos jogos figurados. Em síntese, se os jogos de exercício são a base para o 'como', os jogos simbólicos são a base para o 'porque'. Mas. A coordenação entre o como e o porque só se dará com a estrutura de jogos seguintes, graças à assimilação recíproca.

A fase intuitiva é onde o jogo passa a ter valoração absoluta para a criança, aqui os questionamentos são constantes. O que o desenvolvimento mental é evidenciado pela concepção continuada, semelhante à de um prédio enorme, que se torna mais resistente a cada nova tomada de consciência (PIAGET, 1975).

Nesta fase os jogos obtêm destaque como incentivador dos esquemas visuais, auditivos e cenestésicos que chamamos de perceptivos e também da imaginação, 
lateralidade, síntese, causa efeito etc., que chamamos de operativos ou eficazes. Tais funções, inseridas com as estimulações psicomotoras, definem aspectos básico para o domínio da lecto-escrita, auxiliando no processo de alfabetização. Ainda com relação aos jogos, as crianças já conseguem realizá-los, porém sem observar suas regras.

$\mathrm{Na}$ fase seguinte, denominada de operação concreta, a criança pensa com certa lógica, sua ação se torna mais consciente. Aqui a criança já se encontra com o raciocínio mais evoluído, por assim dizer, a criança se torna criativa. A escola se torna para a criança essência de sua formação. No jogo, a criança está mais do que nunca centrada, não só na sua realização, mas também à disciplina no cumprimento de suas regras. Por fim, a fase operação formal, caracteriza-se pela conquista do novo pelas crianças, os jogos intelectuais. Os jogos de regras, a prática da discussão, o exercício da expressão corporal e da linguagem, possibilitam uma nova visão de mundo, uma nova postura. (Piaget, 1975). Os jogos de regras surgem por volta dos sete anos. Eles contêm como propriedades fundamentais de seu sistema, as duas características herdadas das estruturas anteriores.

Na condição de invariante do sistema, a regularidade do jogo deve ser levada em consideração por todos os participantes, sendo a transgressão das regras uma falta grave, que perturba o sentido do jogo. Os jogos de regra são combinados arbitrários, criados pelo inventor do jogo ou por seus componentes, que os jogadores aceitam livremente.

Mas há algo que é original e próprio à estrutura dos jogos de regra: seu caráter coletivo, ou seja, nessa estrutura só se pode jogar em função da jogada do outro. Os jogadores, nesse sentido, sempre dependem um do outro. Por isso a ideia de assimilação recíproca. Nos jogos de regra o valor lúdico das práticas segue apresentando uma relevância primordial. O período, o local, as normas, etc., são medidas, ainda que fortuitas, que estabelecem as ações mutuas dos integrantes do jogo.

O lúdico além de colaborar e influenciar diretamente na formação da criança, possibilitando um crescimento sério, também é importante para a vida, pois ajuda na solução de questões sobre o movimento corpóreo, discriminações, similitudes e mudanças culturais.

\section{A brincadeira Como Fator Primordial na Ludicidade}


A brincadeira, desde muito cedo, está presente nas atividades das crianças. Entretanto, ele nem sempre proporciona as mesmas gratificações, nem sempre possui as mesmas finalidades. A criança gosta de brincar pela satisfação que a brincadeira a ela proporciona. Ela não encaixa um pote dentro do outro pelo que resulta, mas pelo prazer que sente em estar realizando tal ação. É uma atividade em que a satisfação encontra-se no próprio processo: a brincadeira. Devido à importância do brinquedo afirma-se que:

O brinquedo não é um aspecto predominante na infância, mas um fator muito importante do desenvolvimento. Assim, frequentemente descreve-se o desenvolvimento da criança como o de suas funções intelectuais, toda a criança apresenta-se como um teórico, caracterizado pelo nível de desenvolvimento intelectual superior ou inferior que se desloca de um estágio para outro (VYGOTSKY, 1998, p. 109).

Porém, se ignoradas as carência da criança e a motivação que são capazes para colocá-la em atividade, as pessoas jamais poderão compreender a evolução de um estágio de desenvolvimento da criança para a outra, porque toda evolução esta conectada a uma transformação acentuada nos estímulos, inclinações e valores.. Aquilo que há de interesse para o bebê deixa de interessar a uma criança um pouco maior. É enorme a influência do brinquedo e da brincadeira no desenvolvimento de uma criança, pois:

É no brinquedo que a criança aprende a agir numa esfera cognitiva, ao invés de numa esfera visual externa, dependendo das motivações e tendências internas, e não dos incentivos fornecidos pelos objetos externos. (...) os objetos ditam à criança o que ela tem que fazer: uma porta solicita que abrem e fechem, uma escada que a subam. (VYGOTSKY, 1989, p. 109-110).

Há, nesse caso, uma íntima relação entre aquilo que a criança percebe e a motivação que esta percepção desperta. Ocorre, assim, a manifestação das características psicológicas, a criança motiva-se para agir. Outra característica da criança de primeira infância é a incapacidade de destacar conceito daquele que está observando habitualmente. É irreal pra ela falar que sua mãe saiu para ocupar-se à medida que de verdade estão jogando juntas.

É somente na idade pré-escolar que esta cisão acontece, quando a criança consegue lidar com representações, ocasião em que suas ações não são mais motivadas por aquilo que imagina ser possível fazer com eles. Surgem então as brincadeiras que envolvem o imaginário, o faz-de-conta, onde um pedaço de pau pode ser visto como uma arma ou simplesmente um microfone. E a depender da 
imaginação e da forma que está brincando e do envolvimento da mesma com o brinquedo é que isso pode acontecer. Vale salientar, que nem sempre o objeto usado por ela pode ser utilizado como representação de outro.

É preciso que, com ele, possam ser realizadas ações parecidas às que seriam realizadas com objetos reais. Uma tesoura não pode ser um volante de carro, porque não dá para fazer com ela as ações exigidas para guiar um automóvel; no entanto um objeto circular, como uma tampa de panela ou uma peneira desempenha muito bem este papel. Um copo não pode ser um cavalo, porque é impossível fazer com ele ações que o assemelham com um cavalo, etc. Estas são situações em que a criança opera com significados, ou seja, o pedaço de madeira não é madeira é "revólver"; a tampa de panela não é uma tampa, é "volante".

Quando uma criança encena o papel de mãe através de uma brincadeira de casinha tendo a sua boneca como filha, faz algumas permissões à boneca (autoriza que use maquiagem, coma chocolate no momento que almoça, etc) o que faz transparecer deveres, aos quais na realidade não são suportados por ela. As aprendizagens superiores de uma criança são obtidas no ato de brincar, aprendizagens essas que futuramente transformam-se em um grau relevante de atuação entre o real e a moral.

\section{Considerações Finais}

Acredita-se na influência do espaço lúdico na construção do conhecimento do educando, onde o jogo, o brinquedo e a brincadeira são elementos indispensáveis para o avanço da aprendizagem. E o professor credibiliza o conhecimento prévio do aprendente, estabelecendo vínculo entre o conhecimento empírico e cientifico.

A prática do lúdico é de extrema importância na prática educativa, considerando de extrema importância a inserção do lúdico no processo de aprendizagem do educando. Com relação ao brinquedo e o jogo como suporte na aprendizagem constata-se sua utilização e relevância imprescindível no desenvolvimento físico, intelectual e sócio afetivo do aprendente. Faz-se necessário que o educador utilize o lúdico de forma pedagógica, atentando para seus objetivos e funções na prática educativa.

Respondendo ao questionamento realizado no início da pesquisa pode-se afirmar que o lúdico é caracterizado como elemento indispensável na prática 
pedagógica das classes investigativas, e mais do que nunca é vital a conscientização do sentido real do lúdico na aprendizagem e no desenvolvimento do ser humano. Constata-se o fato de que de acordo com a coleta de dados os docentes e coordenadores credibilizam o brincar no seu espaço educativo, concedendo ao seu educando oportunidade de apreender o conhecimento com prazer e alegria.

Salienta-se ainda a formação docente relacionada ao lúdico, como cerne para o aprimoramento da prática pedagógica, para que dessa forma o educador possa ter segurança no momento de desenvolver essa prática. Entretanto, registra-se aqui a necessidade dos educadores estarem de sobreaviso para que façam cada vez mais um argumento defensivo, pela relevância da mediação lúdica junto aos pais, na busca de uma sensibilização consciente acerca dos benefícios dos momentos intencionais do brincar, visto que agregam os aspectos essenciais ao desenvolvimento infantil.

\section{Referências:}

BRASIL. Ministério da Educação e Cultura. Parâmetros Curriculares Nacionais. Brasília : MEC, SEB, 1997.

BRASIL. LDB - Lei de Diretrizes e Bases da Educação Nacional. Lei no 9.394/96 de 20 de dezembro de 1996. - Brasília : MEC, SEB, 1996.

BROUGÉRE, G. Brinquedo e Cultura. 5aㅡ. ed., São Paulo, Cortez, 2004.

BITTENCOURT, G. KISHIMOTO, T. M. Jogos Infantis: 0 jogo, a criança e a educação. 10ª ed. Petropolis, RJ: Vozes, 1993.

FREINET, E. As técnicas Freinet ds escola moderna. Trad: Silva Letra. $4^{\mathrm{a}}$ ed. Lisboa: Estampa, 1975.

FREIRE, P. Alfabetização e conscientização. Porto Alegre: Editora Emma,1963.

HUIZINGA, J. Homo ludens: o jogo como elemento da cultura. São Paulo: Perspectiva; Edusp, 1971.

INCONTRI, D. Pestalozzi: educação e ética. São Paulo: Scipione, 1997.

KISHIMOTO, T. M. Jogos infantis: o jogo, a criança e a educação. Petrópolis, RJ: Vozes, 1993.

KISHIMOTO, T. M. Jogo, brinquedo, brincadeira e a educação. São Paulo: Cortês, 1994.

MACEDO, L; PETTY, A. L S; PASSOS, N. C. Os jogos e o lúdico na Aprendizagem Escolar. $2^{\mathrm{a}}$ ed. Porto Alegre. Artmed, 2005.

MONTESSORI, M. Pedagogia científica: a descoberta da nova criança. São Paulo: Flamboyant, 1970.

NISBET, J. Ensinar e aprender a pensar: uma (re)visão temática. Brasília: Universidade de Brasília, 1992.

NICOLAU, M. L. M. A educação pré -escolar, fundamentos e didática. São Paulo: Ática, 1998.

OLIVEIRA, Z. M. R. de. Educação Infantil: fundamentos e métodos. $7^{\text {a }}$ ed. São Paulo; Cortez, 2011. 
PIAGET, J. O Tempo e o Desenvolvimento Intelectual da Criança. Rio de Janeiro: Forense,1973.

PIAGET, J. A formação do símbolo na criança. Rio de Janeiro: Editora Zahar, 1975. PIAGET, J. A psicologia da criança. Ed. Rio de Janeiro. Bertrand Brasil, 1998.

ROUSSEAU, J. J. Emílio ou da educação. São Paulo: Martins Fontes, 1995.

TEIXEIRA, C. E. J. A ludicidade na escola. São Paulo: Loyola, 1995.

VYGOTSKY, L. S. Aprendizagem, desenvolvimento e linguagem. $2^{\mathrm{a}}$ ed. São Paulo: Ícone, 1998.

VYGOTSKY, L. S. Aprendizagem e desenvolvimento na Idade Escolar. Linguagem, desenvolvimento e aprendizagem. 11aㅡ ed. São Paulo: Ícone, 2010.

VYGOTSKI, L.S. Psicología Infantil. Obras Escogidas. Tomo IV. Madrid: Aprendizaje Visor, 2005. 